\title{
Mapping of Soil Properties Using Geographical Information System (GIS): A Case Study of Hassan Usman Katsina Polytechnic
}

\author{
Jafar Adam1, Samaila Saleh ${ }^{1}$, Adekunle T. Olowosulu², Ahmed H. Ashara², S. Srividhya ${ }^{3}$ \\ ${ }^{1}$ Department of Civil Engineering, Hassan Usman Katsina Polytechnic, Katsina, Nigeria \\ ${ }^{2}$ Department of Civil Engineering, Ahmadu Bello University, Zaria, Nigeria \\ ${ }^{3}$ Department of Civil Engineering, SRM University, Chennai, India \\ Email: *samailasaleh2003@yahoo.com
}

How to cite this paper: Adam, J., Saleh, S., Olowosulu, A.T., Ashara, A.H. and Srividhya, S. (2018) Mapping of Soil Properties Using Geographical Information System (GIS): A Case Study of Hassan Usman Katsina Polytechnic. Open Journal of Civil Engineering, 8, 544-554.

https://doi.org/10.4236/ojce.2018.84039

Received: September 1, 2018

Accepted: December 22, 2018

Published: December 25, 2018

Copyright () 2018 by authors and Scientific Research Publishing Inc. This work is licensed under the Creative Commons Attribution International License (CC BY 4.0).

http://creativecommons.org/licenses/by/4.0/

\begin{abstract}
GIS relates and integrates spatial data from various sources, for storage, retrieval, analyses and display. This paper presents the analysis and mapping of Geotechnical data using natural neighbour interpolation tool of GIS. The Campus of Hassan Usman Katsina Polytechnic Nigeria was as the study area, and Arc GIS 10.2.1 was used to perform the analyses. The study used soils samples from ten trial pit distributed within the study area and subjected to various laboratory tests. Index and engineering properties of the samples were determined. Map database developed in a GIS environment and the result of the laboratory tests stored, were analysed and displayed using GIS. The research results show maps of various soil properties. The research result provides estimated data for preliminary designing of engineering infrastructures in the area.
\end{abstract}

\section{Keywords}

Geographic Information System, Soil Properties and Hassan Usman Katsina Polytechnic

\section{Introduction}

Index and engineering properties of soil, for example, specific gravity, moisture content, dry density, bulk density, permeability, compressibility, and shear strength are among the geotechnical parameters. The said parameters may change between places. Civil engineers need to know about the variation of the index and engineering properties of soil before carrying out design and con- 
struction of an engineering structure. Field or laboratory soil testing will provide a result which is too specific for a particular location to generalise over an extended area. Geotechnical engineers investigate the behaviour of soils under different conditions. The duties of geotechnical engineers also include but not limited to assessing and designing of slopes, excavations and foundations [1].

Engineering data especially that used by geotechnical engineers are costly, and difficult to obtain and analyse. It is difficult to determine the soil types and change of layers at every point on the site. Engineers depend on information from representative samples to estimate the soil properties. In this regards, a method of analysing and mapping soil properties using GIS and GPS in the study area (Hassan Usman Katsina Polytechnic Katsina State Nigeria) attempted in the paper. The following objectives achieved the aim of the paper:

1) Obtaining soil samples from the representative trial pits, and testing the soil properties for each location chosen.

2) Digitizing and developing the study area map.

3) Developing the map database of soil test results and analysis of result using Arc GIS 10.2.1 software.

\section{Literature Review}

Application of GIS in Civil and Geotechnical Engineering is receiving much interest in the current literature. Hallowell et al. (2012) [2] highlighted the GIS application by reviewing case studies. The three GIS components identified by the authors are databases, graphics interfaces and data analysis. A method of mapping the swelling potential of soil was developed using GIS by [3]. The research used a digital map of a region, data from the area and GIS to propose zoning of maps, evaluate various mechanisms that caused soil swelling and indicate an area with high and low-risk of soil swelling. The maps are used in the development planning and in reducing the risk of damage caused by soil swelling. The cost of constructing projects also reduces by permitting designers to avoid places with dangers for soils swelling.

Player [4] as cited by [5] introduced applications of GIS technology in geological hazards identification. The research planned and tracked field work. Communication improved by creating figures and maps. Foyer et al. [6] estimated recharge using GIS that identifying possible combinations of soil type and vegetation. In Athens of Greece, [7] reported the application of GIS to produce thematic maps of the geotechnical, geological, seismological and geomorphological data of the area. In Brazil, [8] used GIS for geotechnical and environmental risk management of oil pipeline. Thiesen [9] conducted GIS Mapping of geotechnical data of Blumenaui city in Brazil using a digital terrain model. The result provided information on the geographic features and urban growth.

Furthermore, [10] reviewed the application of GIS in Geotechnical Engineering. The review covered the capabilities and uses of the technology of GIS in Civil Engineering. Other similar researches were carried out using numerous 
applications of GIS like those by [11]-[21]. However, application GIS for mapping soil properties for use in preliminary design is limited in the literature. Given that, an effort is made here, to conduct Mapping of Soil Properties using natural neighbour interpolation tool of GIS in the case study of Hassan Usman Katsina Polytechnic Nigeria.

\section{Methodology}

The methodology used in this study was in three phases. The first stage was the field exploration and laboratory test. This involved activities like site exploration, feasibility survey of the study area, obtaining the samples and performing the prescribed tests in a laboratory. Ten numbers of trials pits were collected within the study area and tested for index and engineering properties as per standard procedures of [22]-[28]. The trial pits were distributed correctly within the study area in order to obtain a representative cross-section of the area. The depths of the trial pits were made more than the depth of foundation most existing building in the study area. The second stage was the digitisation and development of the study area map in ArcGIS. Satellite image of the area obtained from google earth digitised and geo-referenced in Arc map. Coordinates of some control points were obtained using handheld GPS and used to geo-referenced the map.

The last stage of the research was database creation and analysis of results. Map database was created using arc catalogue and uploading the tested results of the borrow pits in the database. Other spatial and non-spatial attributes of the study area also recorded, and the map was updated accordingly. Natural neighbour interpolation tool was used in performing the analyses that resulted in obtaining maps of various properties of soil. The natural neighbor interpolation tool is also called "Sibson" or "area-stealing". The procedure of using the tool involves catching the nearby subcategory of input models to the point of enquiry and putting weights to them based on comparable areas to incorporate a value [29]. In other words, the closest subset of input samples of a point in question are defined, and weights are applied to them based on proportionate areas, and their values are interpolated. The properties of natural neighbor interpolation tool are local because it only uses a subset of samples that border the inquiry point, and the interpolated heights are within the range of the models used. Natural neighbor interpolation tool neither deduces trends nor yield peaks not embodied by the input samples. The result is uniform all over the place except at positions of the input samples. The weights assigned to the input point are scores comparative to the significance of each input samples.

\section{Results and Discussions}

Taking samples at every position in the study area for investigation of soil property could be very expensive. As a substitute, a measure of the soil properties of the representative sample at selected locations and then predicting other values 
in all other locations using the natural neighbour interpolation tool of GIS can save cost and time. Input points (trial pits) were spaced correctly based on a sampling scheme. The properties of soils at the sample points uploaded in the map database then analysed and presented in results (Figures 1(a)-(j)).

Figure 1(a) shows the distribution of natural moisture content over the study area. Colours variation denoted the result; each colour layer indicates range per cent of moisture content; the darker the colour, the higher the moisture content in the area. Similarly, Figure 1(b) shows the distribution of the liquid limit over the study area. The various colours ranges indicate the amount of moisture content present in the area. The variation in the moisture content was due to the variation in the soil type. The area with loose soils showed lower natural moisture content as well as and lower values of liquid limit, plastic limit, linear shrinkage and CBR as shown in Figures $1(\mathrm{~b})$-(d) and Figure 1(j) respectively. Borrow Pit no 3 with lighter colour has lower moisture content about 3\% while Borrow pit no 8 and 9 have higher moisture content about 9\%.

The distribution of the amount of fine-grained particles (smaller the 0.075 $\mathrm{mm}$ ) existing in the samples is shown in Figure 1(e). Area near Borrow Pit 9 and 10 contain about $5 \%$ of fine grain particles and that was due to the presence of residual soils in those areas that can be confirmed by the higher CBR value of about $50 \%$ as shown in Figure 1(j). Furthermore, Figure 1(g) and Figure 1(h) show the distribution of compaction characteristics (maximum dry density,

NATURAL MOISTURE CONTENT MAP

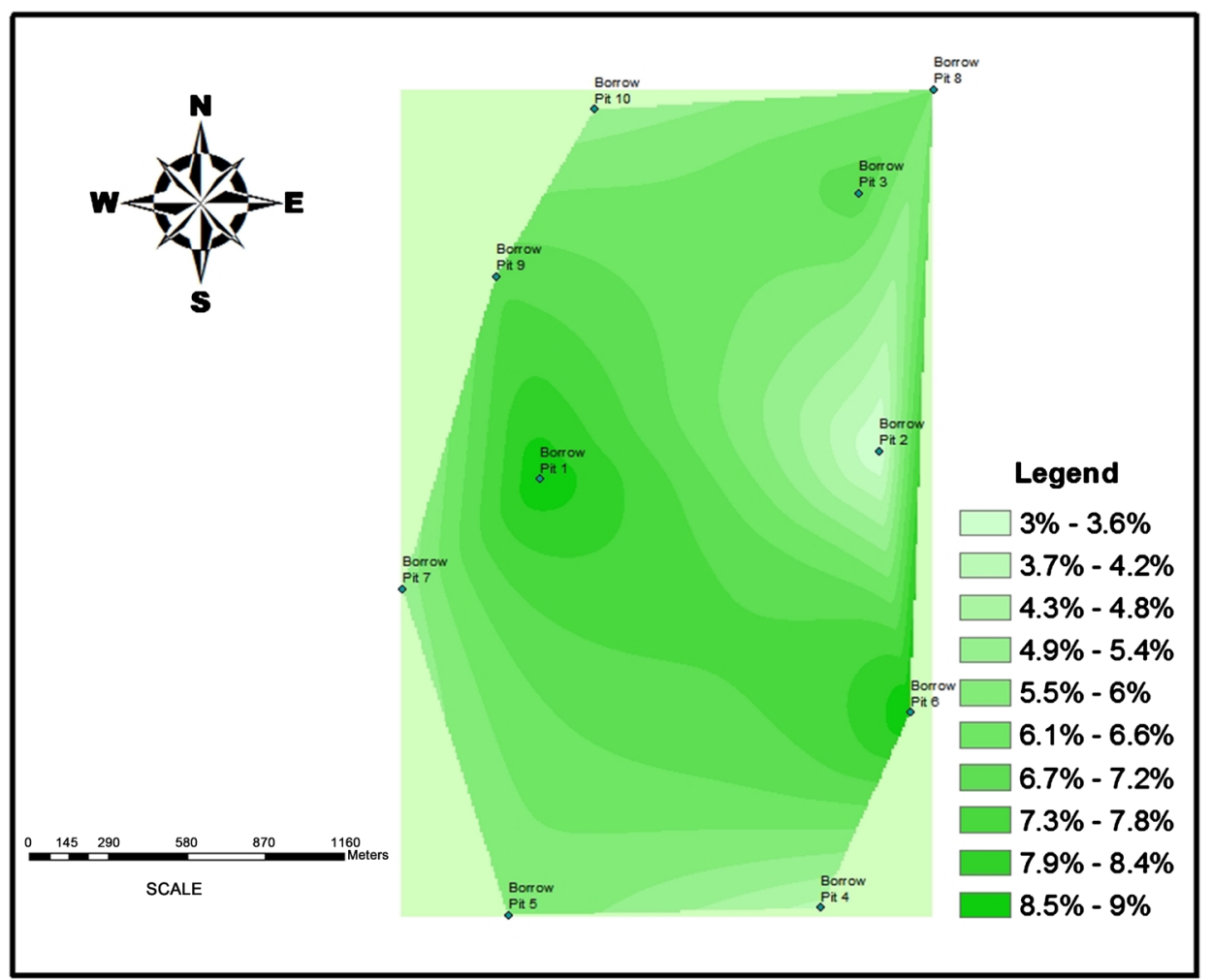

(a) 
LIQUID LIMIT MAP

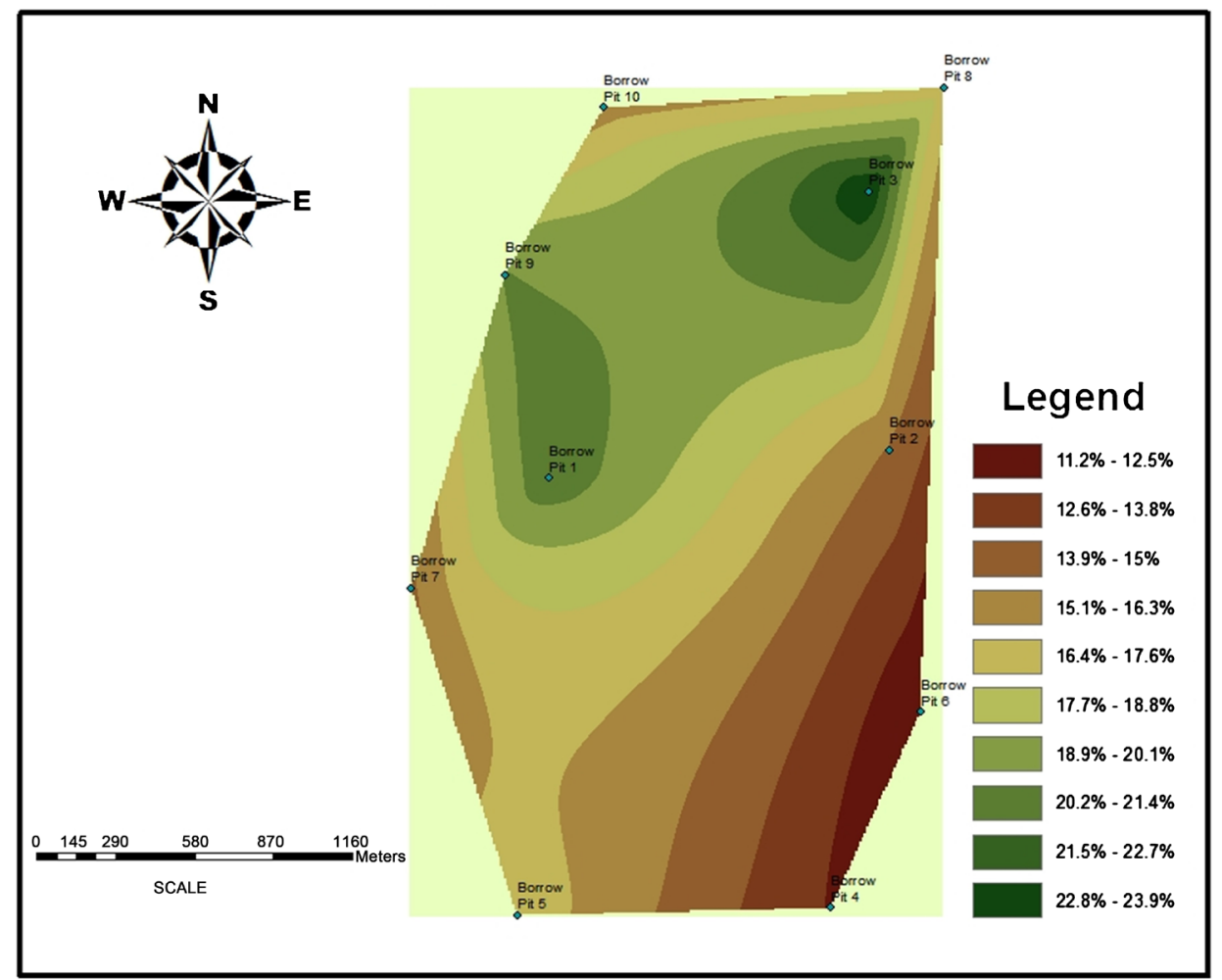

(b)

PLASTIC LIMIT MAP

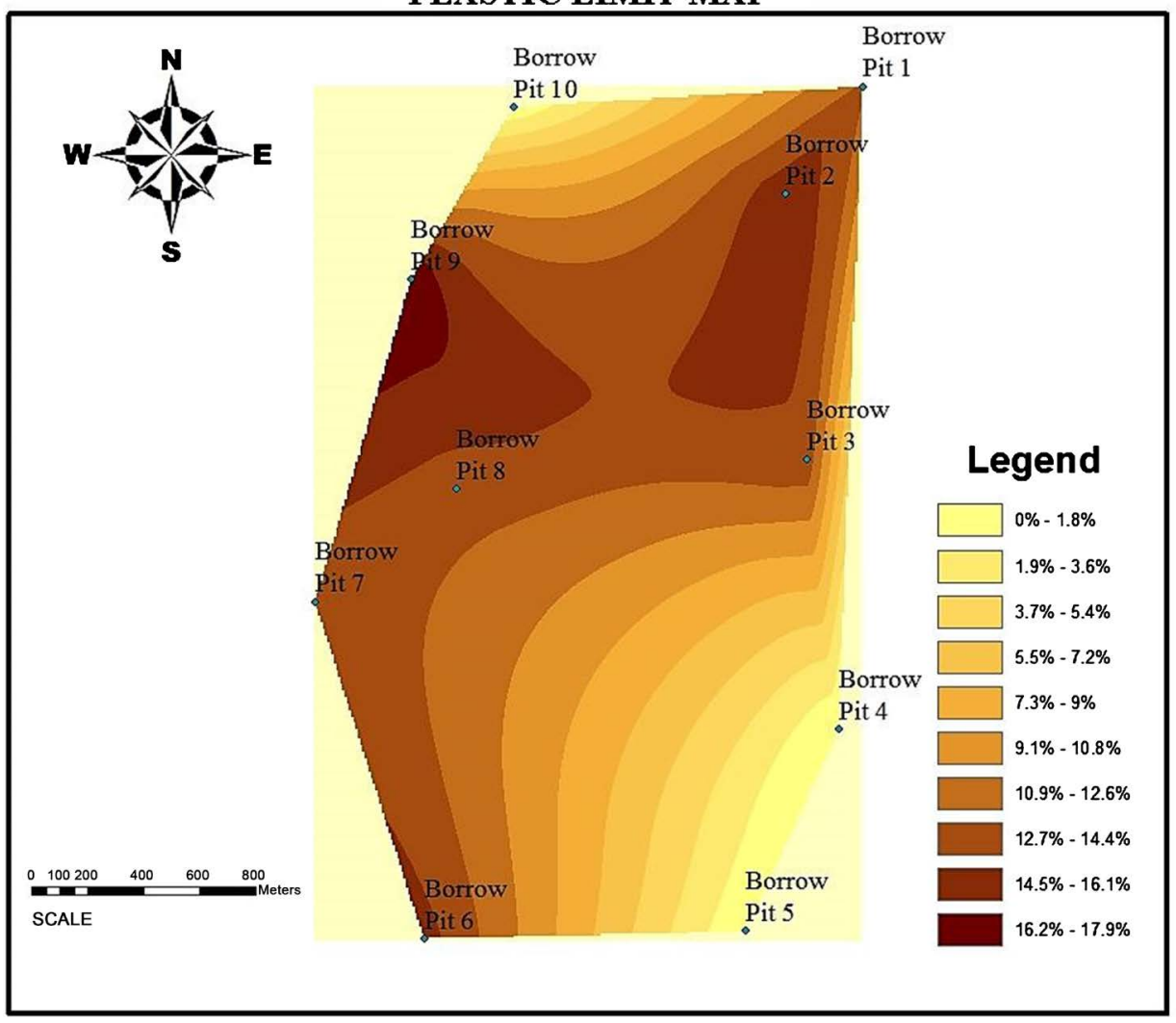

(c) 


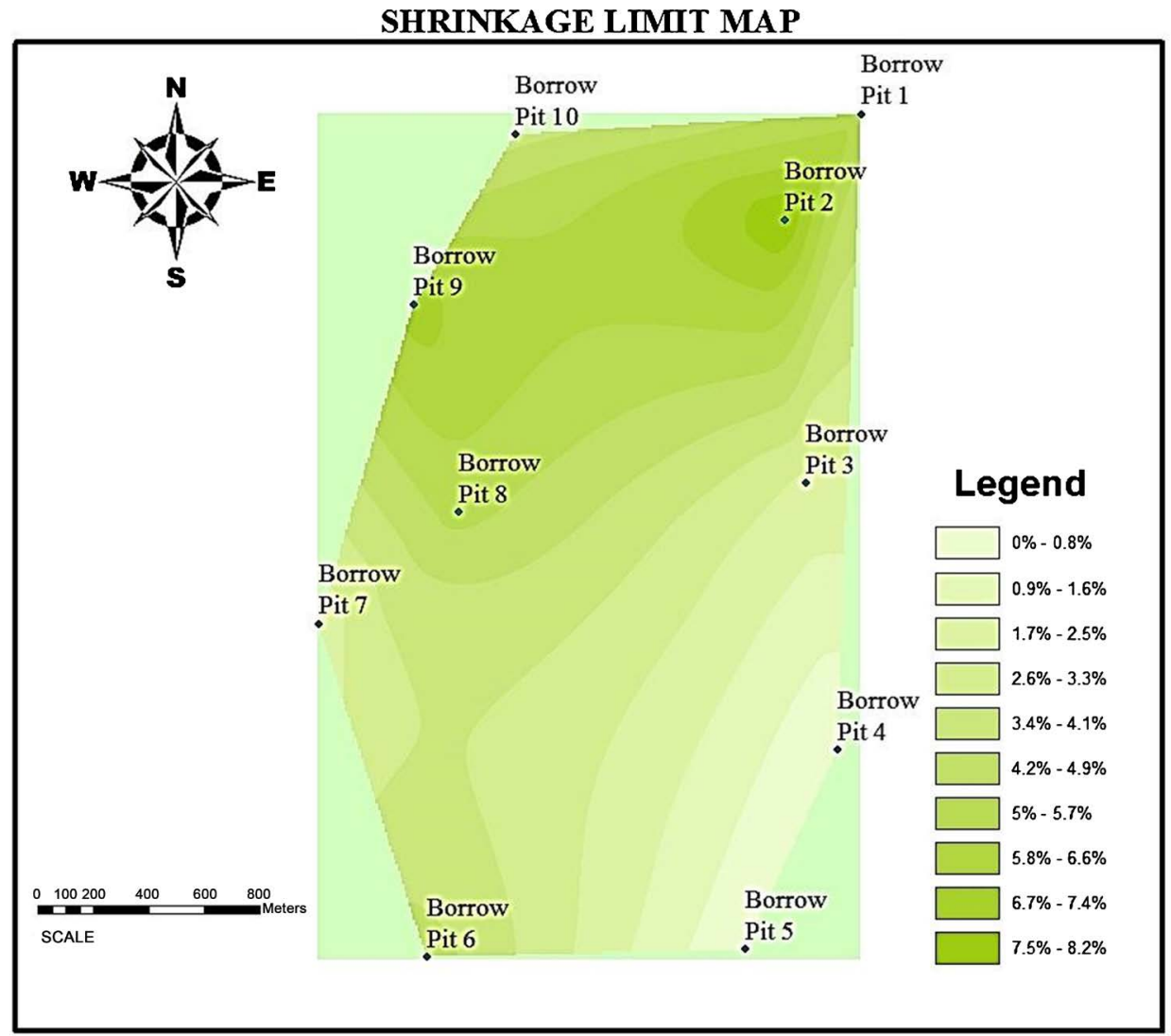

(d)

SIEVE ANALYSIS MAP (\% passing No. 0.075 sieve)

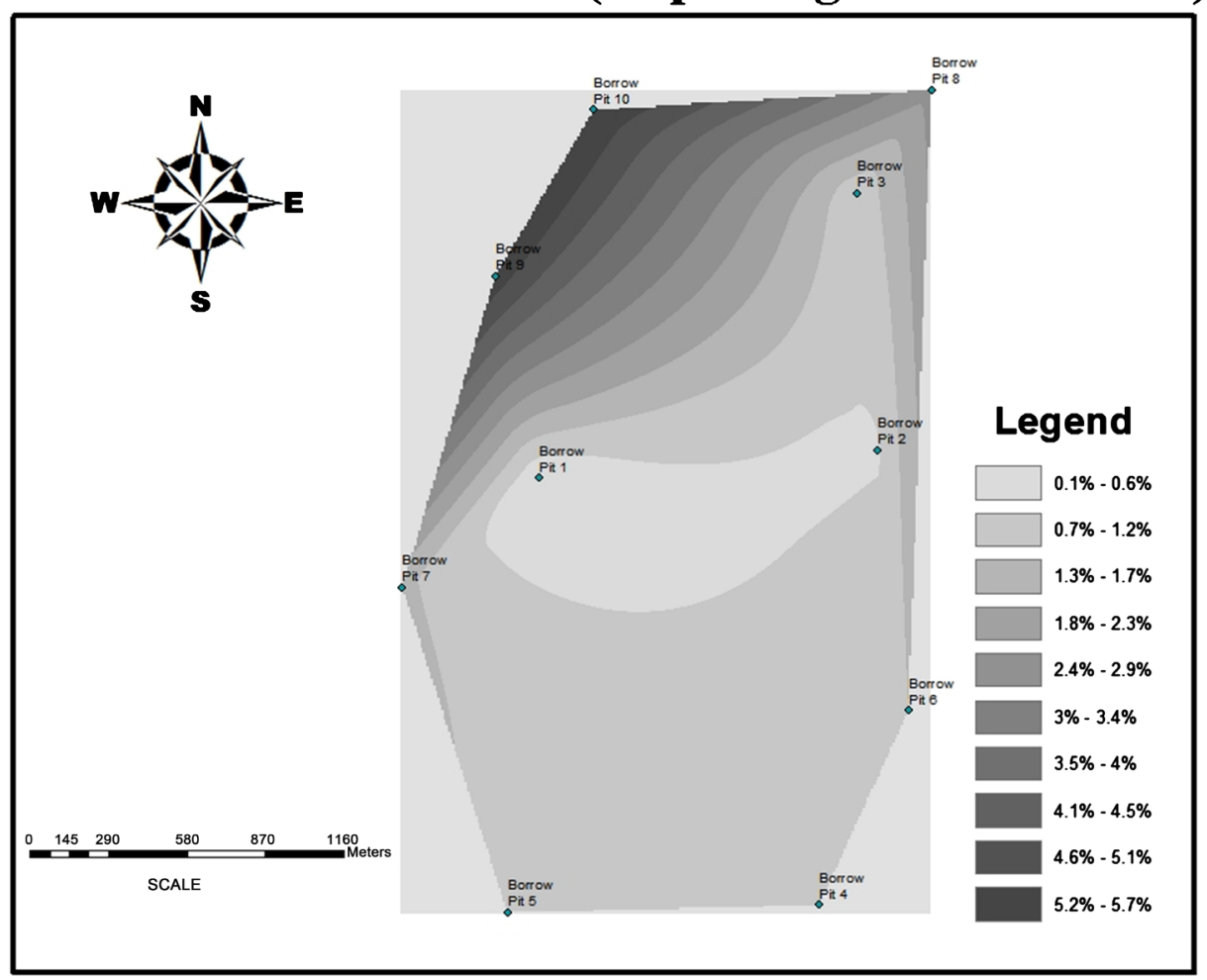

(e) 
SIEVE ANALYSIS MAP (\% passing No. 2.36 sieve)

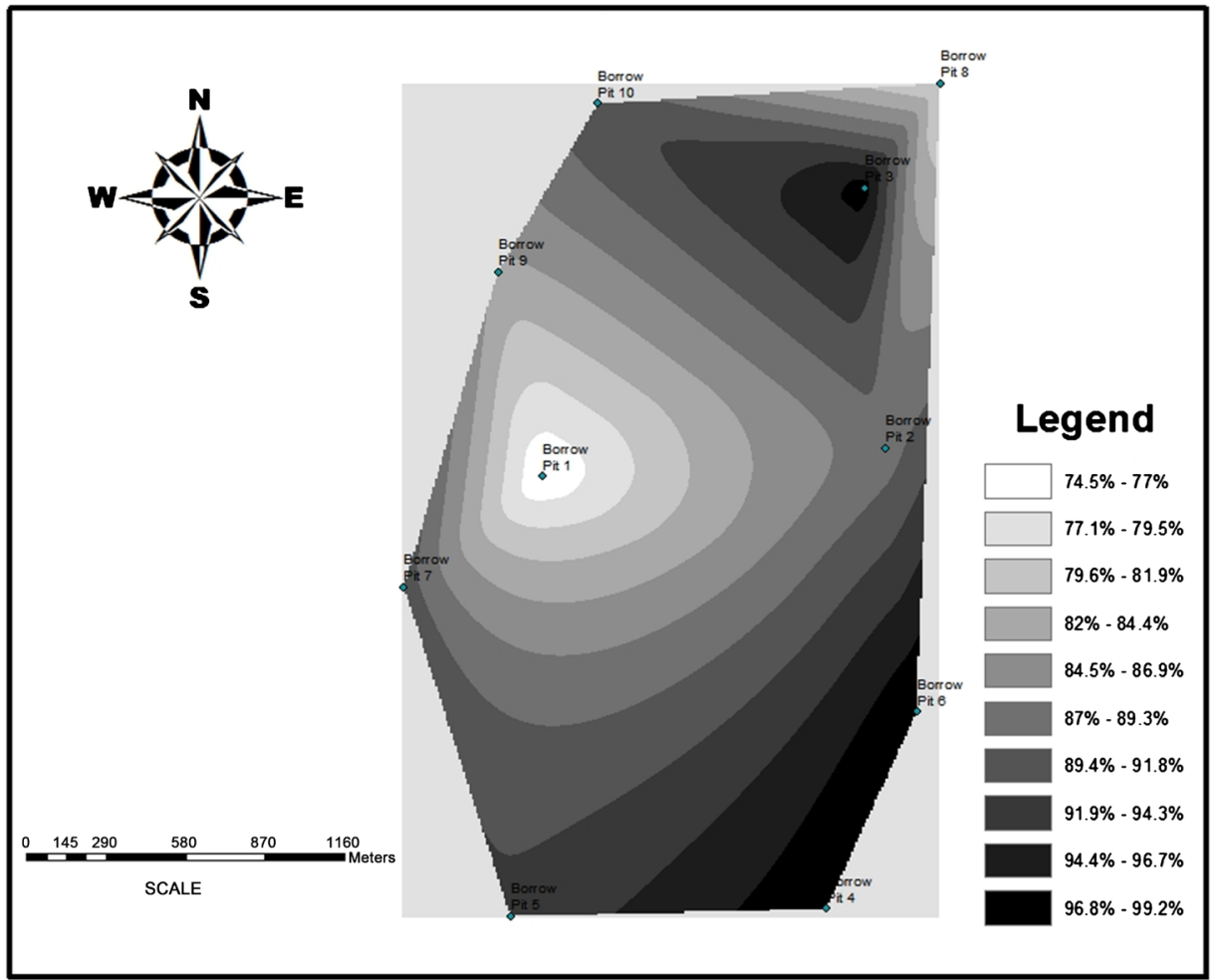

(f)

MAXIMUM DRY DENSITY MAP

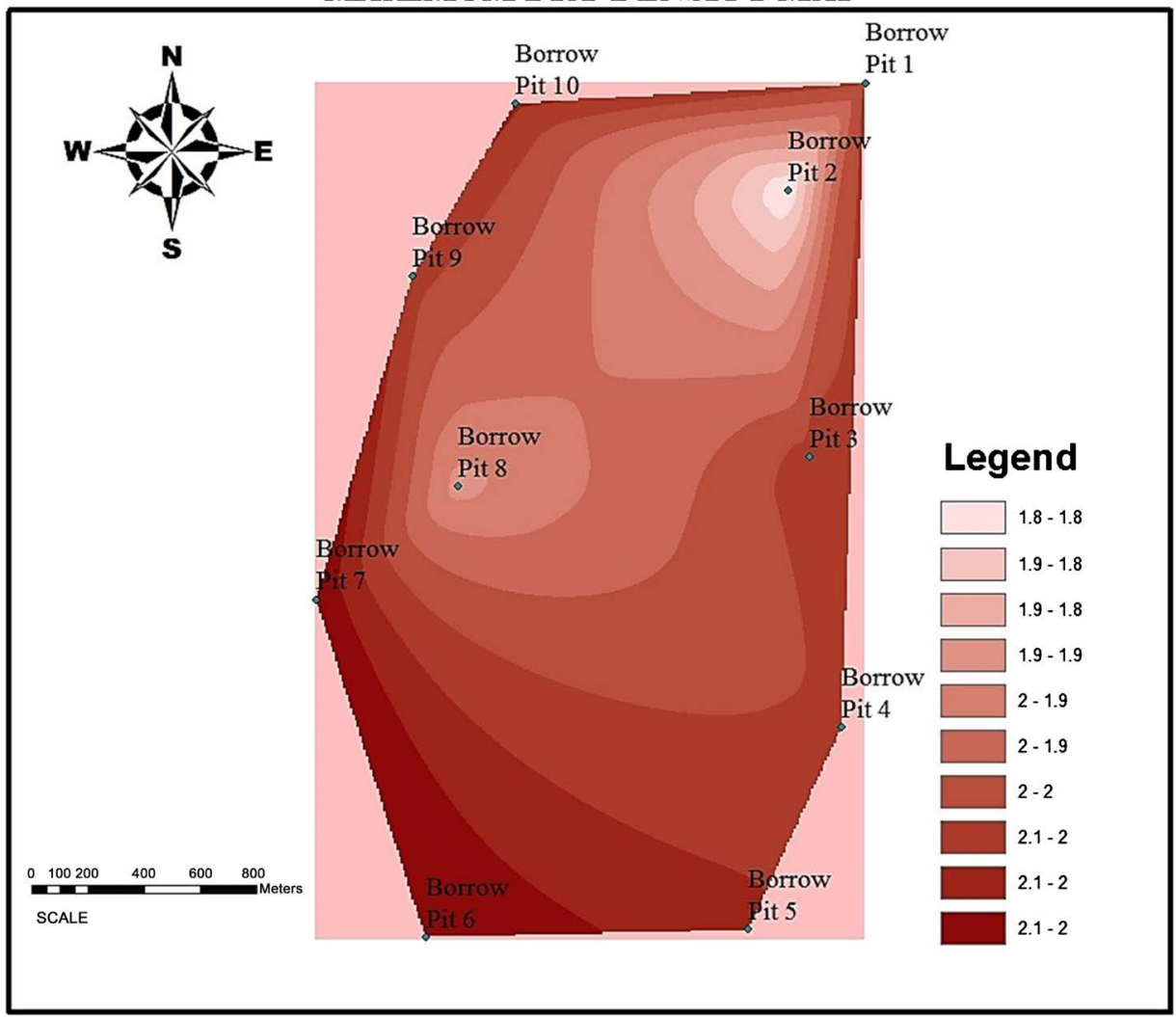

(g) 
OPTIMUM MOISTURE CONTENT MAP

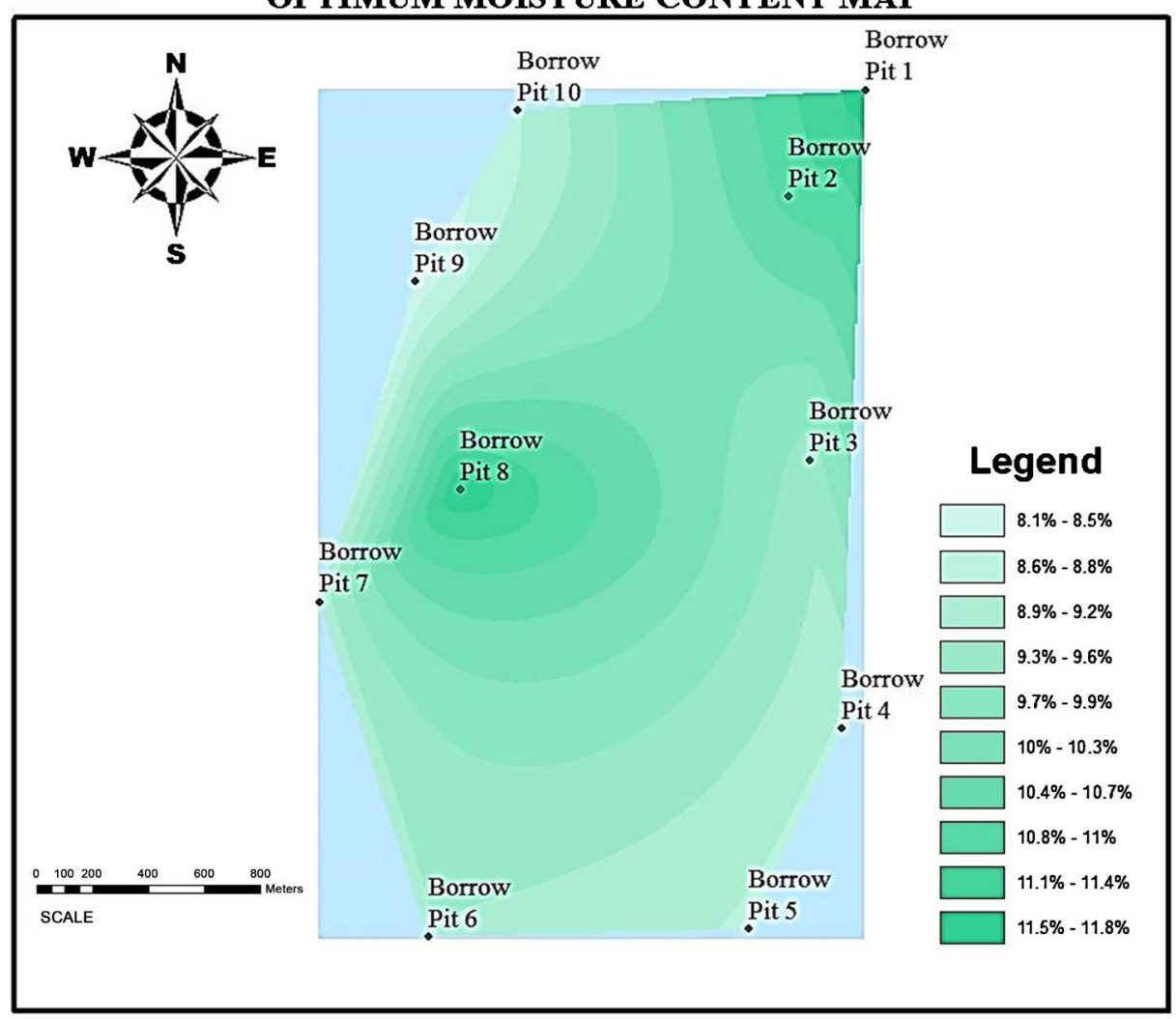

(h)

SPECIFIC GRAVITY MAP

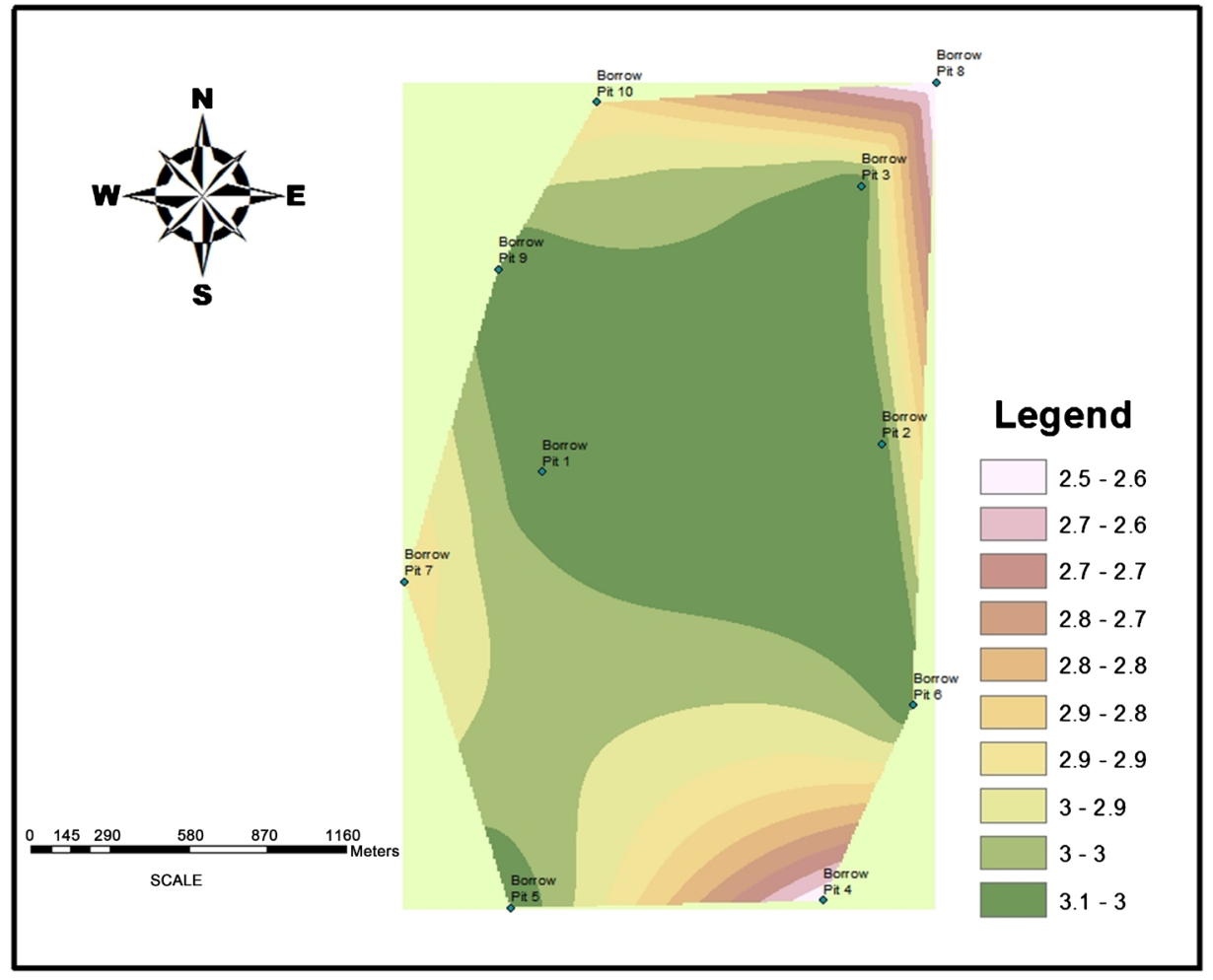

(i) 
CBR Value MAP

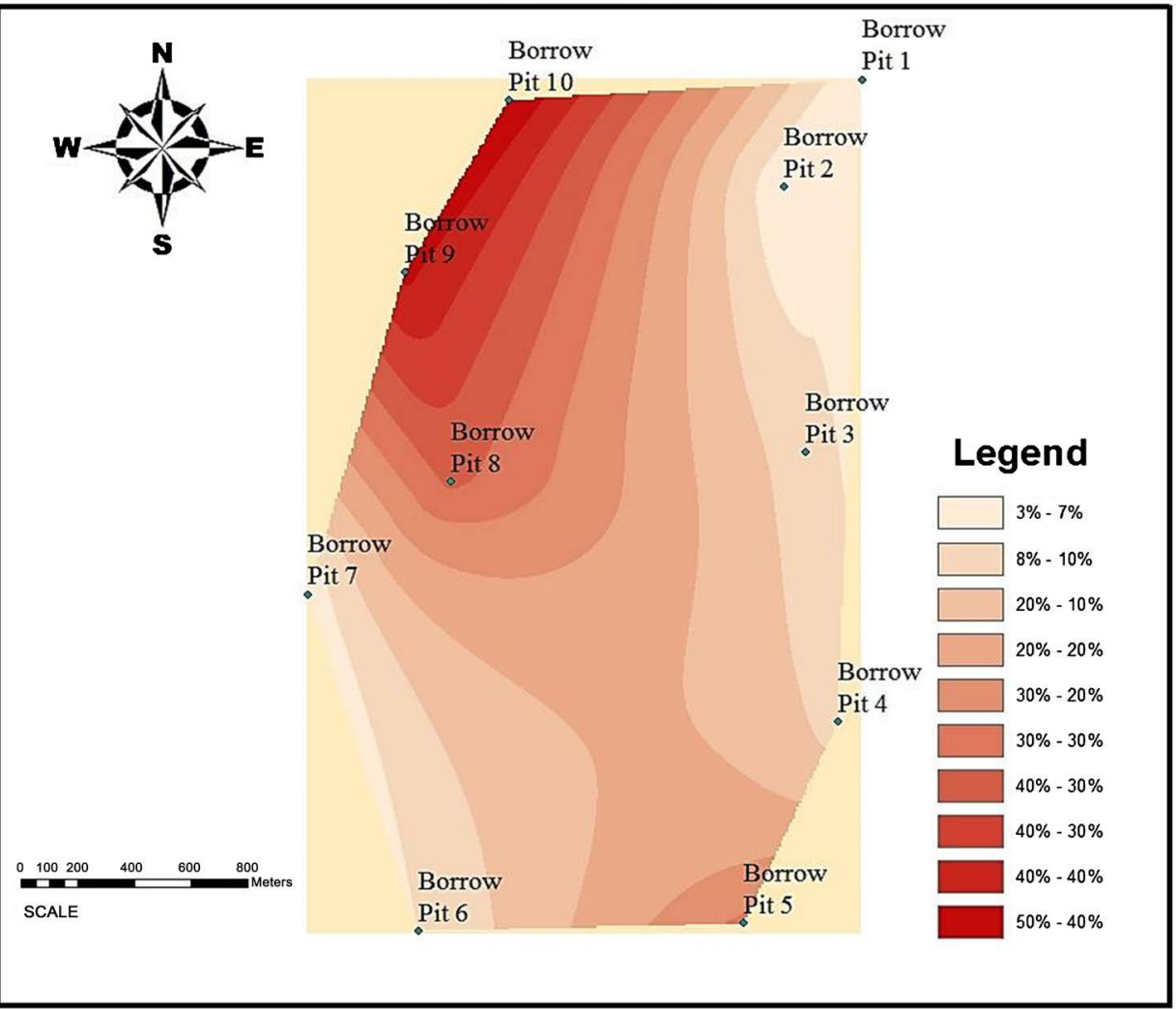

(j)

Figure 1. Distributions of the soil properties over the study area. (a) Natural moisture content; (b) Liquid limit; (c) Plastic limit test; (d) Linear shrinkage; (e) Percent finer than sieve No 200 (size $0.075 \mathrm{~mm}$ ); (f) Percent finer than sieve no 10 (size $2.00 \mathrm{~mm}$ ); (g) Maximum dry density; (h) Optimum moisture content; (i) Result of specific gravity test; (j) CBR test result.

MDD and optimum moisture content, OMC) in the study area. The area near Borrow Pits 10, 9, 7, 6, 5 and 4 have soil type with higher MDD values and lower OMC value. While area near Borrow Pits 2 and 8 contain is materials with low MMD values and high OMC value. Thus, area near Borrow Pit 10, 9 and 5 contain soil type that is more suitable for construction purposes and are not likely to give trouble to shallow foundation due the high strength symbolized by high $\mathrm{CBR}$ and $\mathrm{MDD}$ values and lower OMC values about $50 \%, 2 \mathrm{Mg} / \mathrm{m}^{3}$ and $8.8 \%$ respectively as shown in Figure $1(\mathrm{j})$, Figure $1(\mathrm{~g})$ and Figure $1(\mathrm{~h})$.

\section{Conclusions}

This research work on Mapping of Soil Properties using Geographic Information System (GIS) (A Case Study of Hassan Usman Katsina Polytechnic) was successfully implemented with the following conclusion:

A GIS-based user-friendly system developed using application of Natural Neighbor Interpolation Tool can assist to easily and quickly produce the maps of different themes based on soil properties. The valuable information about soil properties within the study area obtained is suitable preliminary designs pur- 
pose.

The system can provide a means of identifying areas with suitable construction material in the study area. Furthermore, areas with potential foundation problem within the study area can also be easily identified and avoided during the feasibility studies of future development.

\section{Conflicts of Interest}

The authors declare no conflicts of interest regarding the publication of this paper.

\section{References}

[1] Marc, V. (2012) Implication of GIS and RS in Geotechnical Mapping. NRS-509. http://www.edc.uri.edu/nrs/classes/nrs409509/509_2012/MVigeant.pdf

[2] Hallowell, E.E., Lamont, B.J., Kemp, A.C. and Hughes, J. (2001) GIS as a Tool in Geotechnical Engineering. Proceedings of the Institution of Civil Engineers. Geotechnical Engineering, 149, 85-93.

[3] Orhan, A. and Tosun, H. (2010) Visualization of Geotechnical Data Using Geographic Information System: A Case Study in Eskisehir City (NW Turkey). Journal of Environmental Earth Sciences, 61, 455-465. https://doi.org/10.1007/s12665-009-0357-1

[4] Player, R. (2006) Geographic Information System (GIS) Use in Geotechnical Engineering. Proceedings of Geo-Congress, Atlanta, 26 February-1 March 2006, 1-6.

[5] Alaeddinne, E. (2013) Using Geographic Information System (GIS) in Soil Classification and Analysis in Gaza City, Palestine. Journal Environmental and Natural Resources Research, 3, 146-159.

[6] Fayer, M.J., Gee, G.W., Rockhold, M.L., Freshly, M.D. and Walters, T.B. (1995) Estimating Recharge Rates for a Groundwater Model Using GIS. Journal of Environmental Quality, 25, 510-518.

[7] Antoniou, A.A., Papadimitriou, A.G. and Tsiambaos, G. (2008) Geographical Information System Managing Geotechnical Data for Athens (Greece) and Its Use for Automated Seismic Micro Zonation. Journal of Natural Hazards, 47, 369-395. https://doi.org/10.1007/s11069-008-9226-6

[8] Augusto, F.O., Hirai, J.N., Oliveira, A.S. and Liotti, E.S. (2010) GIS Applied to Geotechnical and Environmental Risk Management in a Brazilian Oil Pipeline. Bulletin of Engineering Geology and the Environment, 69, 631-641. https://doi.org/10.1007/s10064-010-0310-2

[9] Thiesen, S., Santos, J.V. and Higashi, R.R. (2015) Application of GIS Tools for Geotechnical Mapping-A Case Study in Brazil. International Conference on Geotechnical Engineering, Colombo, 10-11August 2015, 1-5.

[10] Sharma, Y., Purohit, D.G.M. and Sharma, S. (2017) Applicability Aspects of Geoinformatics in Geotechnical Engineering. American Journal of Engineering Research $(A J E R), 6,71-75$.

[11] Elisabeth, N.B., Keith, R.J., Chris, J.M. and John, W. (1996) Use of Soil Survey Information to Assess Regional Salinization Risk Using Geographical Information System. Journal of Environmental Quality, 25, 433-439.

https://doi.org/10.2134/jeq1996.253433x 
[12] Kulkarni, M.N. (2003) Global Positioning System and Its Application, Five-Day CEP Course. Department of Civil Engineering, IIT Bombay, Mumbai, 1-15.

[13] Kothari, U.C. and Jain, S.K. (1997) Sediment Yield Estimation Using GIS. Journal of Hydrological Sciences, 42, 833-843 https://doi.org/10.1080/02626669709492082

[14] Meijerink, A.M.J., Vav Lieshout, A.M. and Mobareke, F.R. (1996) Comparison of Approaches for Erosion Modeling Using Flow Accumulation with GIS. HydroGIS 96: Application of GIS System in Hydrology and Water Resource Management. Proceedings of the Vienna Conference, Vienna, April 1996, 437-444.

[15] Look, B.G. (2007) Handbook of Geotechnical Investigation and Design Tables. Chapter 5, Taylor \& Francis Group, London, 55. https://doi.org/10.1201/9780203946602

[16] Lok, M. (1987) LOGS A Prototype Expert System to Determine Stratification Profile from Multiple Boring Logs. Master's Thesis, Department of Civil Engineering, Carnegie Mellon University, Pittsburgh.

[17] Oliphant, J. and Jowitt, P.W. (1996) ASSIST A Computer-Based Advisory System for Site Investigations. Proceeding ICE: Geotechnical Engineering, 119, 109-122. https://doi.org/10.1680/igeng.1996.28170

[18] Rahman, S., Munn, L.C., Vance, G.F. and Arneson, C. (1997) Wyoming Rocky Mountain Forest Soils: Mapping Using an Arc Info Geographical Information System. Journal of Soil Science Society, 61, 1730-1737.

[19] Rehak, D.R. (1984) An Electronic Workbench for Geotechnical Site Characterization. Research Showcase at CMU. Dept. of Civil and Environmental Engineering Carnegie Institute of Technology, New York.

[20] Sumedh, Y.M. and Deepankar, C. (2009) Application of GIS-GPS for Mapping Soil Index Properties.

[21] Williams, T., Szary, P., Thomann, T., Konnerth, C. and Nemeth, E. (2002) GIS Applications in Geotechnical Engineering. New Jersey Department of Transportation, Ewing.

[22] IS 2720 (1983) Part I: Method for Soil Preparation of Dry Soil Sample for Various Tests.

[23] IS: 2720 (1973) Part II: Method of Test for Soils, Determination of the Water Content.

[24] IS 2720 (1980) Part III: Method of Test for Soils, Determination of Specific Gravity for Fine, Medium and Coarse-Grained Soils.

[25] IS 2720 (1985) Part IV: Method of Test for Soils, Grain Size Analysis.

[26] IS 2720 (1985) Part V: Method of Test for Soils, Determination of Liquid and Plastic Limits.

[27] IS (1980) 2720 Part VII: Method of Test for Soils, Determination of Water Content Dry Density Relationship Using Light Compaction.

[28] IS 2720 (1987) Part XVI: Method of Test for Soils, Laboratory Determination of CBR.

[29] Sibson, R. (1981) A Brief Description of Natural Neighbor Interpolation, Interpolating Multivariate Data. Chapter 2, John Wiley \& Sons, New York, 21-36. 